\title{
Museo Nacional de Arquitectura, México: 30 años de preservación y divulgación del patrimonio artístico inmueble
}

Museo Nacional de Arquitectura (The National Museum of Architecture), Mexico: 30 Years of Preservation and Dissemination of Built Artistic Heritage

\section{Cecilia Sánchez Zárate}

Museo Nacional de Arquitectura (MNA)

Instituto Nacional de Bellas Artes (INBA), México

arq_c_sanchez@prodigy.net.mx

\section{Resumen}

Rescatar, documentar y difundir la arquitectura mexicana e internacional, y a sus protagonistas, es la misión que el Museo Nacional de Arquitectura (MNA), Instituto Nacional de Bellas Artes (INBA, México), ha llevado a cabo desde hace 30 años. A través de una biblioteca, fototeca y planoteca, cuyo acervo reúne más de 6000 planos originales, entre los que destaca el material gráfico original del Palacio de Bellas Artes (PBA-INBA) un programa de exposiciones temporales, tanto en su sede como itinerantes, publicaciones, conferencias, mesas redondas y presentaciones de libros de afamadas personalidades de los ámbitos arquitectónico y del patrimonio cultural; este museo pone en contacto a los profesionales, estudiantes y al público en general con temas del quehacer arquitectónico a escala nacional e internacional. Esta SEMBLANZA esboza la historia, actualidad y retos del MNA-INBA en su vocación de sensibilizar a la sociedad acerca de la riqueza arquitectónica de México y, recientemente, de otras partes del mundo, así como de divulgarla y difundirla para presentes y futuras generaciones.

\section{Palabras clave}

arquitectura; exposiciones; Palacio de Bellas Artes; Museo Nacional de Arquitectura; México

\section{Abstract}

For 30 years the Museo Nacional de Arquitectura (MNA, The National Museum of Architecture), Instituto Nacional de Bellas Artes (INBA, National Institute of Fine Arts, México) has been carrying out its mission to rescue, document and disseminate Mexican as well as international architecture, including leading figures in the field. The museum brings professionals, students and the general public in contact with architectonical issues on national and international level through its library, photo library and map archive with more than 6000 original plans -highlight of the collection is the original graphical material of Palacio de Bellas Artes (PBA, Fine Arts Palace), INBA-, and fur- 
thermore a programme of temporary exhibitions at the venue as well as travelling expositions, publications, conferences, round tables and book presentations of famous personalities from the fields of architecture and cultural heritage. This OVERVIEW sketches the history, the present situation and the challenges of MNA-INBA in carrying out their mission to raise society's awareness about Mexico's architectural wealth and, more recently, that of other parts of the world as well as disseminate and highlight this richness for present and future generations.

\section{Key words}

architecture; expositions; Palace of Fine Arts; National Museum of Architecture; Mexico

E el tercer piso de uno de los edificios icónicos de México, el Palacio de Bellas Artes (PBA, Instituto Nacional de Bellas Artes [INBA], México), centro de la expresión cultural nacional y espacio lógico para albergar a una de las bellas artes, se encuentra el Museo Nacional de Arquitectura (MNA), adjunto a la Dirección de Arquitectura y Conservación del Patrimonio Artístico Inmueble (DACPAI, antes Dirección de Arquitectura, DA) del INBA. En sus 30 años de camino recorrido, esta institución hace evidente no sólo su profundo compromiso por conservar, documentar y estudiar el legado de los grandes maestros de la arquitectura mexicana, sino también el propósito de acercar estudiantes, profesionales de la arquitectura y público en general a la riqueza arquitectónica con la que cuenta México, desde las construcciones de las culturas antiguas hasta la arquitectura nacional, e incluso internacional, del siglo XXI. De esta forma, el MNA "pretende crear conciencia del valor de estas edificaciones muchas veces dañadas por simple desconocimiento de su importancia" (INBA 1990:7).

Las sociedades que han habitado a lo largo y ancho, y en el transcurso de varios milenios, lo que hoy llamamos México, se han manifestado con muestras constructivas de gran complejidad en su composición, así en inmuebles individuales y conjuntos como en urbes. Efectivamente, desde la época prehispánica, con la llegada de los españoles y durante el virreinato, en los subsecuentes periodos históricos y hasta la actualidad, los habitantes de nuestro país han generado obras maestras de arquitectura civil y religiosa que han contribuido sustancialmente al reconocimiento de importantes sitios inscritos en la Lista del Patrimonio Mundial de la Organización de las Naciones Unidas para la Educación, la Ciencia y la Cultura (UNESCO), entre las que se encuentran: Teotihuacán, los primeros monasterios del siglo XVI en las laderas del Popocatépetl, el Centro Histórico de la ciudad de México, la Casa-Taller del maestro Luis Barragán y el campus central de la Universidad Nacional Autónoma de México (UNAM, México) (UNESCO 2015) (Figura 1).
Con tal cantidad y diversidad de edificaciones patrimoniales era necesaria la creación de un centro de documentación que rescatara, conservara y divulgara toda la labor de diseño y construcción de los maestros nacionales y extranjeros, y que tuviera como objetivo el estudio de la arquitectura mexicana; de tal forma que, siendo pionero en el continente americano con dos exposiciones previas, $\mathrm{La}$ arquitectura en México: Porfiriato y Movimiento Moderno (1982) y 80 años de la colonia Roma (1983), el 26 de enero de 1984 se inauguró oficialmente el MNA-INBA con una muestra sobre el arquitecto Francisco J. Serrano (INBA 1990:1-2).

Al ser la ventana de difusión de la DACPAI, el MNA-INBA también cuenta con una planoteca, una fototeca y una biblioteca con un acervo de más de 6000 planos originales y otros documentos gráficos, entre los que destaca el material planimétrico original del PBA-INBA correspondiente a su arquitecto, Adamo Boari ${ }^{1}$-el cual estuvo fuera del país a lo largo de casi 70 años-; a éstos se suman otras relevantes colecciones, a seguir:

En 1990 la Sra. Elisa viuda de Del Moral cedió a la Dirección de Arquitectura un invaluable archivo de planos, fotografías y documentos de la autoría de Enrique del Moral; en 1993 la familia del prestigiado arquitecto Carlos Obregón Santacilia entregó a la planoteca de la dirección planos, croquis y fotografías originales de la obra de este protagonista de la arquitectura de siglo XX, además de otros archivos rescatados y restaurados, como el del arquitecto Juan Segura, Juan O'Gorman y Francisco Centeno (INBA 1990:8).

Durante 2012 se inició, con apoyo de tecnología de punta, la digitalización en alta resolución de parte del gran acervo de la DA-INBA, que ha incluido planos, fotografías, dibujos, acuarelas y otros documentos gráficos que, tras su debida investigación, registro y catalogación, además de que podrán ser consultados por estudiantes e investigadores, o bien formar parte de alguna publicación o muestra, han servido para la realización de "exposiciones de gran calidad" (Ortiz Híjar 2014). En mi experiencia como parte del equipo del MNA-INBA, he sido testigo del reto que representa el espacio donde se desarrolla su discurso museográfico: un pasillo en torno del vestíbulo principal, a nivel del tercer piso del edificio, como he dicho, que cubre una limitada área de $5.8 \mathrm{~m}$ de ancho y casi

\footnotetext{
${ }^{1}$ Como es sabido, el Italiano Adamo Boari fue el arquitecto seleccionado para llevar a cabo el proyecto del Gran Teatro Nacional (hoy PBA). Nació en Marrara, pequeño poblado de Ferrara (Italia) en 1863; obtuvo el título de ingeniero civil en 1886. Estableció contactos con la comunidad italiana en México y, entre 1897 y 1900, realizó algunos proyectos en nuestro país. En marzo de 1904 Boari entregó a la Secretaría de Comunicaciones y Obras Públicas un proyecto para el Nuevo Teatro Nacional, compuesto por 18 planos y 2 acuarelas (Leal 2010:165-166).
} 


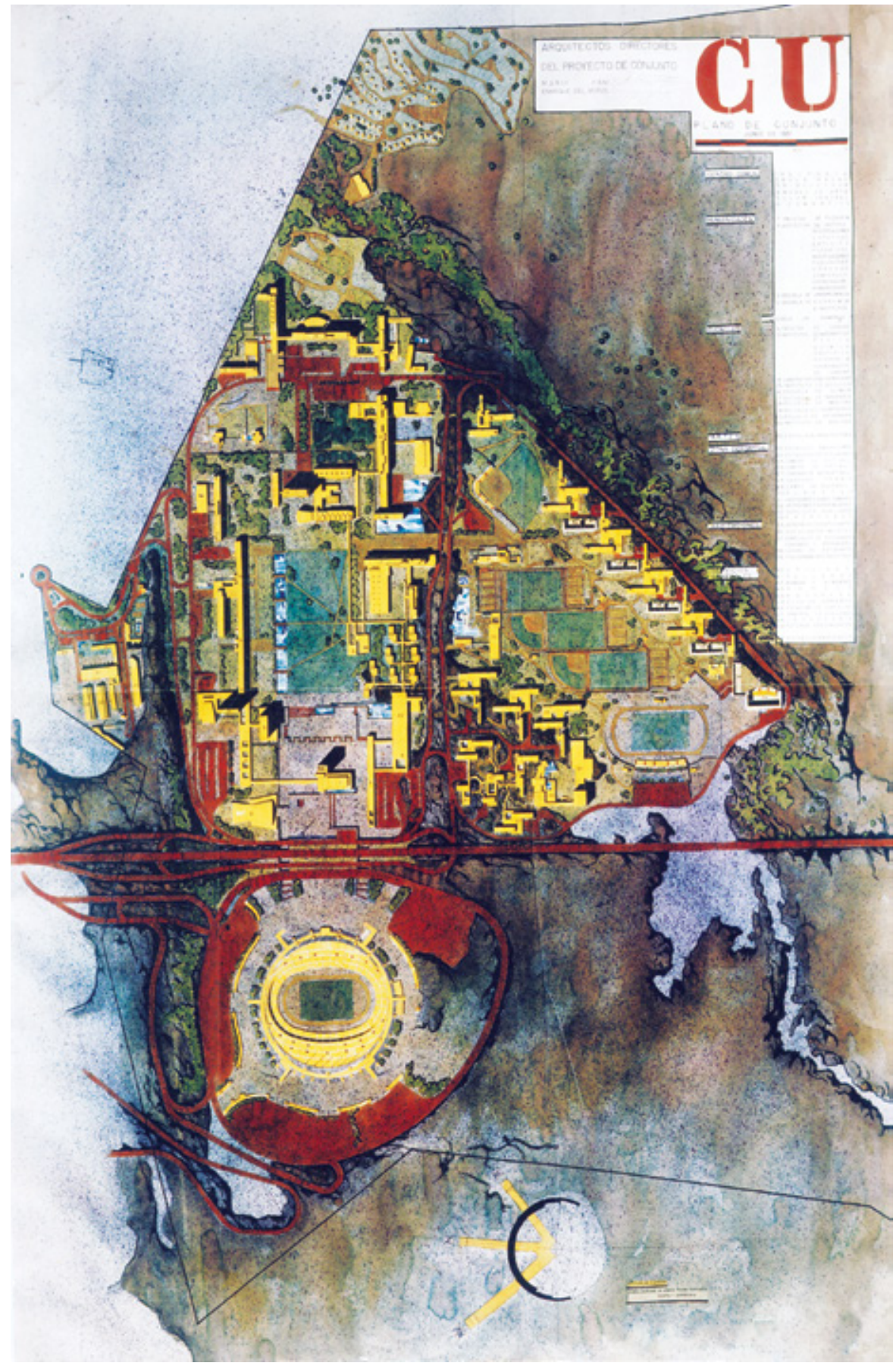

FIGURA 1. Planta de conjunto de la Ciudad Universitaria, México, acuarela de Mario Pani y Enrique del Moral, 1951 (Cortesía: planoteca DACPAI-INBA).

$142 \mathrm{~m}$ lineales, en el que, adicionalmente, existen restricciones para el manejo museográfico no sólo en cuanto a la sujeción de la obra sobre los muros sino también su proximidad con los barandales de bronce, todos ellos elementos originales en el monumento artístico, en materia de tránsito de visitantes. Por ello ha sido necesario desarrollar un diseño museografíco único que respete el espacio, sea autoportante y no obstaculice el paso entre el mobiliario del interior del edificio, para lo cual se ha hecho uso de mamparas móviles, andamios de metal, estructuras tridimensionales de madera, etc., con lo que se ha logrado un recorrido dinámico en un espacio lineal.

Es de notar que estas limitaciones espaciales no sólo han sido superadas por algunas de las muestras presentadas en el MNA-INBA, sino por publicaciones como la serie Documentos para la historia de la arquitectura en México (INBA 1990), cuyos primeros tres números han sido resultado de las exposiciones La construcción del Palacio de Bellas Artes (1984), José Villagrán, arquitecto (1987) y La arquitectura de la Academia (1985) (Martínez Orralde 2014).

Vale asimismo subrayar que "el MNA-INBA ha realizado hasta la fecha un total de 135 exposiciones temporales" (Ortiz Híjar 2014) de temática diversa: dos de ellas, sobre la arquitectura prehispánica: La vivienda azteca en la ciudad de México en los códices-planos de los siglos XVI y XVII (1995) y Tetzcotzinco, arquitectura de paisaje en la época de Netzahualcóyotl (1997) (MNA-INBA 2014:6), mientras que seis se han dedicado al rescate y conservación del patrimonio arquitectónico y urbanístico, entre las que podemos mencionar: Recuperación del patrimonio arquitectónico del siglo XX (1998) y Conservación del patrimonio monumental (1999) (MNA-INBA 2014:8). Respecto de la arquitectura mexicana y sus protagonistas, se han montado 93 muestras, dentro de las cuales sobresalen Los espacios de Diego y Frida (2007); Antonio Pastrana, 1913-1967: 55 años de arquitectura (2008); Fray Gabriel Chávez de la Mora: mística y arte (2010); Abraham Zabludovsky, 1924-2003 (2012) (Figura 2); Primera muestra internacional de iluminación arquitectónica (2013), y Presencia del exilio español en la arquitetura mexicana (2014) (Figura 3), todas ellas con una convocatoria cuyas cifras han alcanzado más de 60000 visitantes (MNA-INBA 2014:13-22).

También en el ámbito internacional es notable la labor del MNA-INBA, con 34 exhibiciones realizadas con el apoyo de instituciones educativas y culturales del extranjero y embajadas como la de Francia, España, Suecia, Japón, 


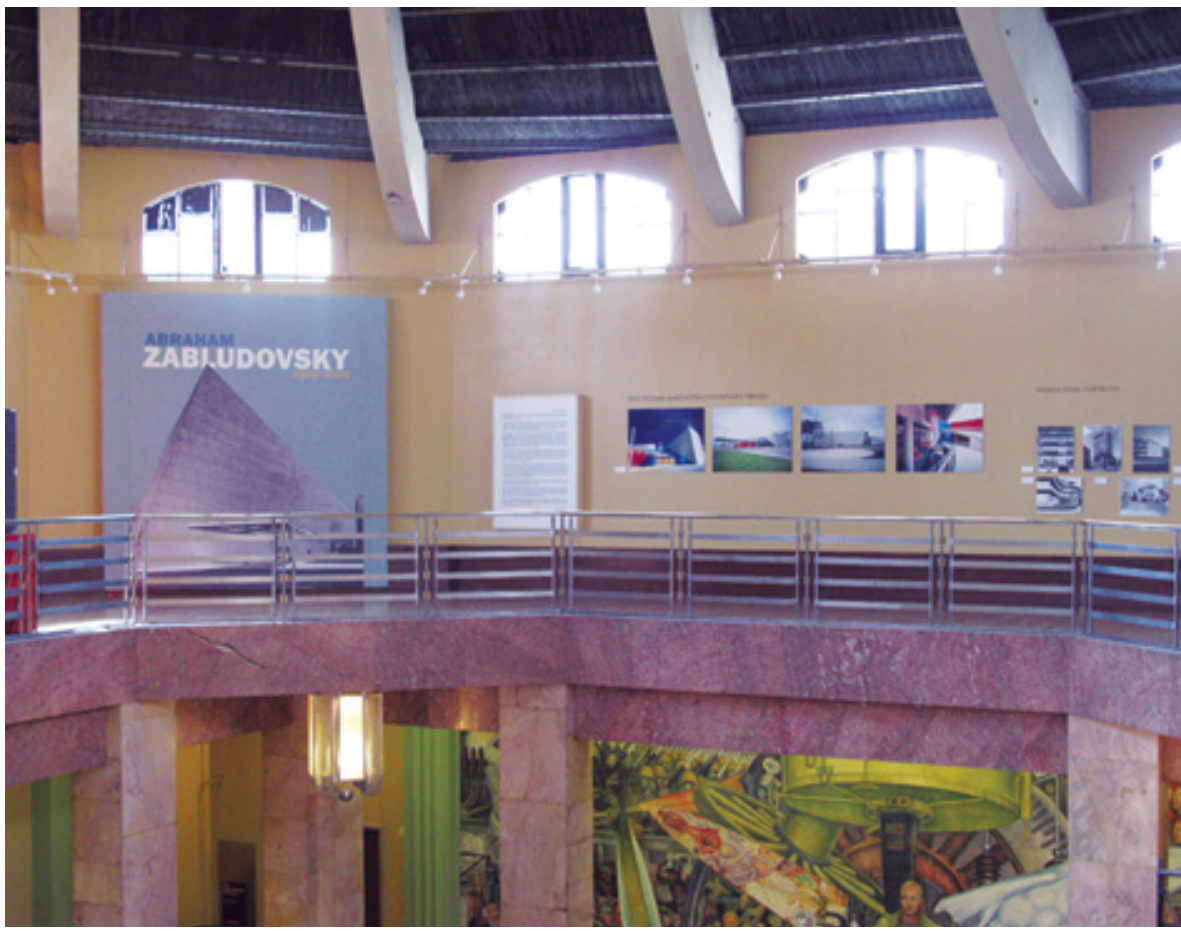

FIGURA 2. Perspectiva de la exposición Abraham Zabludovsky, 1924-2003, en el Museo Nacional de Arquitectura (MNA), Instituto Nacional de Bellas Artes (INBA), México (Fotografía: Josué Flores, 2012; cortesía: fototeca MNA-INBA, DACPAI-INBA).

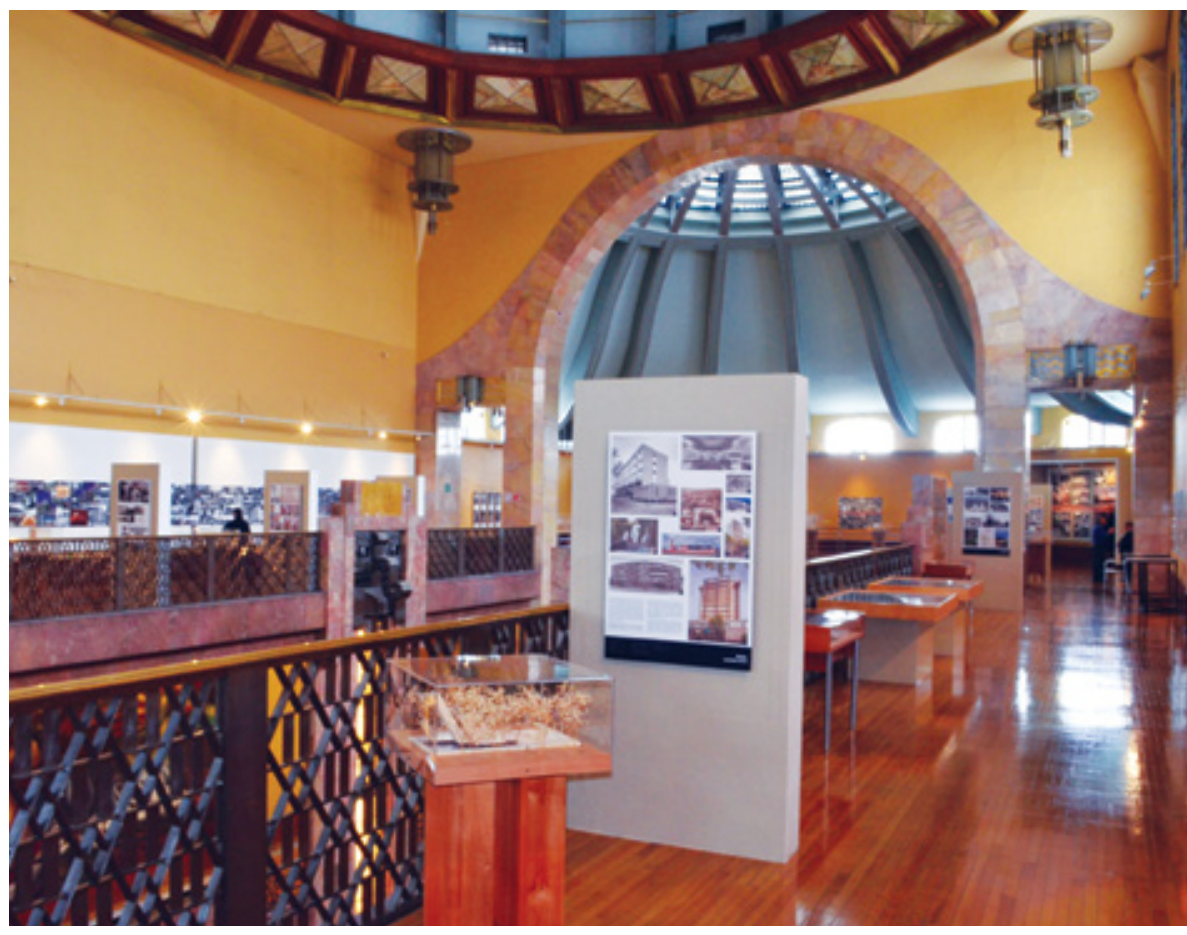

FIGURA 3. Vista general de la exposición Presencia del exilio español en la arquitectura mexicana, MNA-INBA, México (Fotografía: Josué Flores, 2014; cortesía: fototeca MNA-INBA).
Finlandia, Colombia, Italia y Grecia (MNA-INBA 2014:1-22). La última de ellas en colaboración, justamente, con Grecia, denominada Partenón: arquitectura y arte (2013) (MNA-INBA 2014:20), merece una mención especial, ya que su curador, el maestro en arquitectura Aléxandros Apostolákis, de origen heleno, tendió puentes de comunicación entre el MNA-INBA $y$ diferentes instituciones griegas $y$ mexicanas. Así, a través de convenios se permitió el manejo y la exhibición de imágenes de alta resolución de acuarelas, pinturas, grabados y otros materiales gráficos del Museo de la Ciudad de Atenas [MCA], Grecia; de registros de procesos de intervención que se han realizado en el Partenón a lo largo de treinta años, pertenecientes al Museo de la Acrópolis (MA), Grecia (Figura 4), y de videos sobre la tecnología utilizada para la limpieza láser de todos los edificios y esculturas en el sitio arqueológico por parte de la Foundation for Research \& Technology-Hellas (FORTH, Fundación para la Investigación y Tecnología de Hellas, Grecia) (Figura 5). No podemos olvidar al Museo Nacional Arqueológico de Atenas (MNAA), Grecia, que proporcionó la imagen de Pallas Atenea, reproducción de la original que se encontraba en el interior del templo e icono de toda la exposición. Asimismo, es de notar que el Museo Nacional de las Culturas del Instituto Nacional de Antropología e Historia (MNC-INAH, México) prestó dos reproducciones, el busto de una koré y el segmento de una metopa que representa la guerra de los centauros (Figura 6). Cabe mencionar que Partenón: arquitectura y arte ha sido la exposición más exitosa en la historia del MNA-INBA, con casi 90000 visitantes en tan sólo dos meses (MNA-INBA 2014:20).

Además del trabajo expositivo mencionado anteriormente, el MNAINBA realiza conferencias y mesas redondas con personalidades de los ámbitos arquitectónico y del patrimonio cultural, presentaciones de libros, así como, para el público infantil, talleres y cursos de verano que lo acercan a 


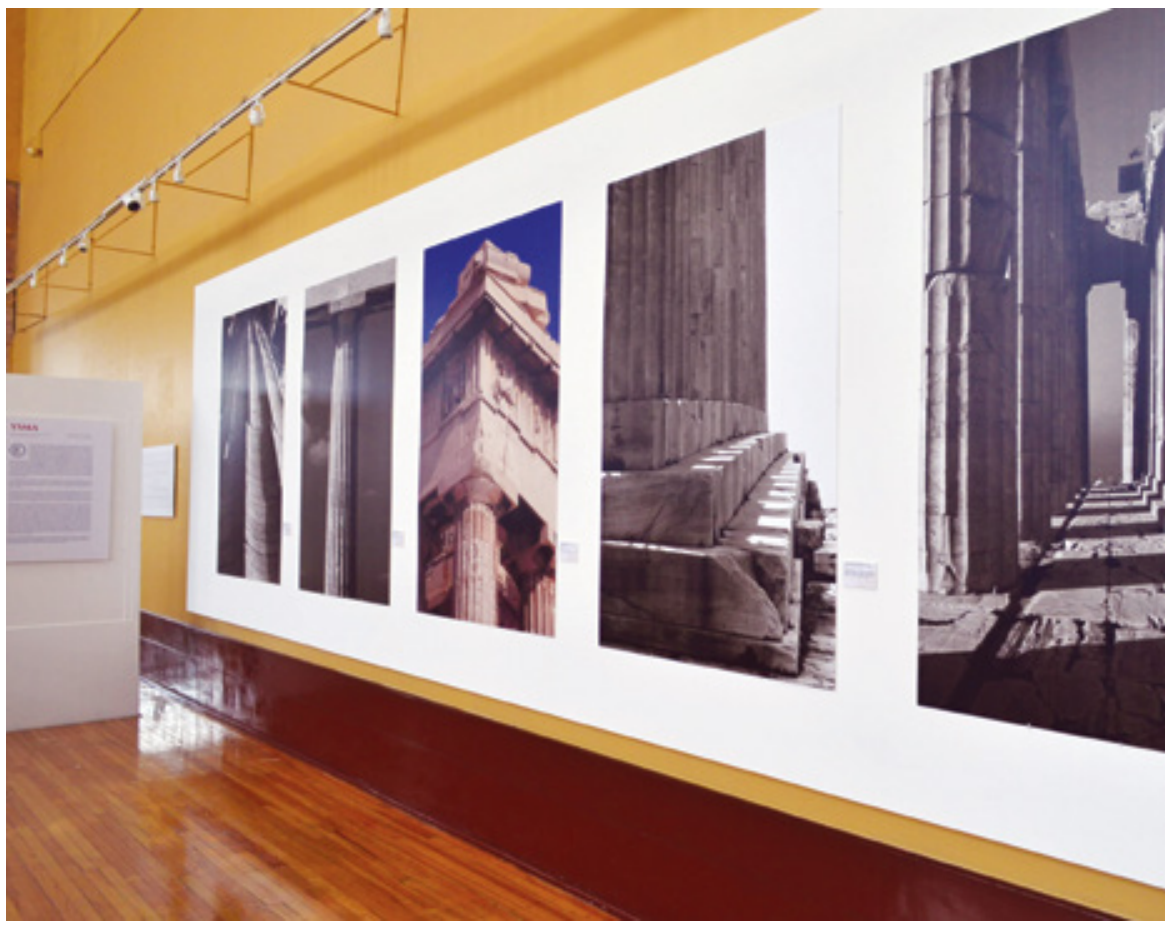

FIGURA 4. Exposición Partenón: arquitectura y arte, muro norte, MNA-INBA, México (Fotografía: Josué Flores, 2013; cortesía: fototeca MNA-INBA, DACPAI-INBA).

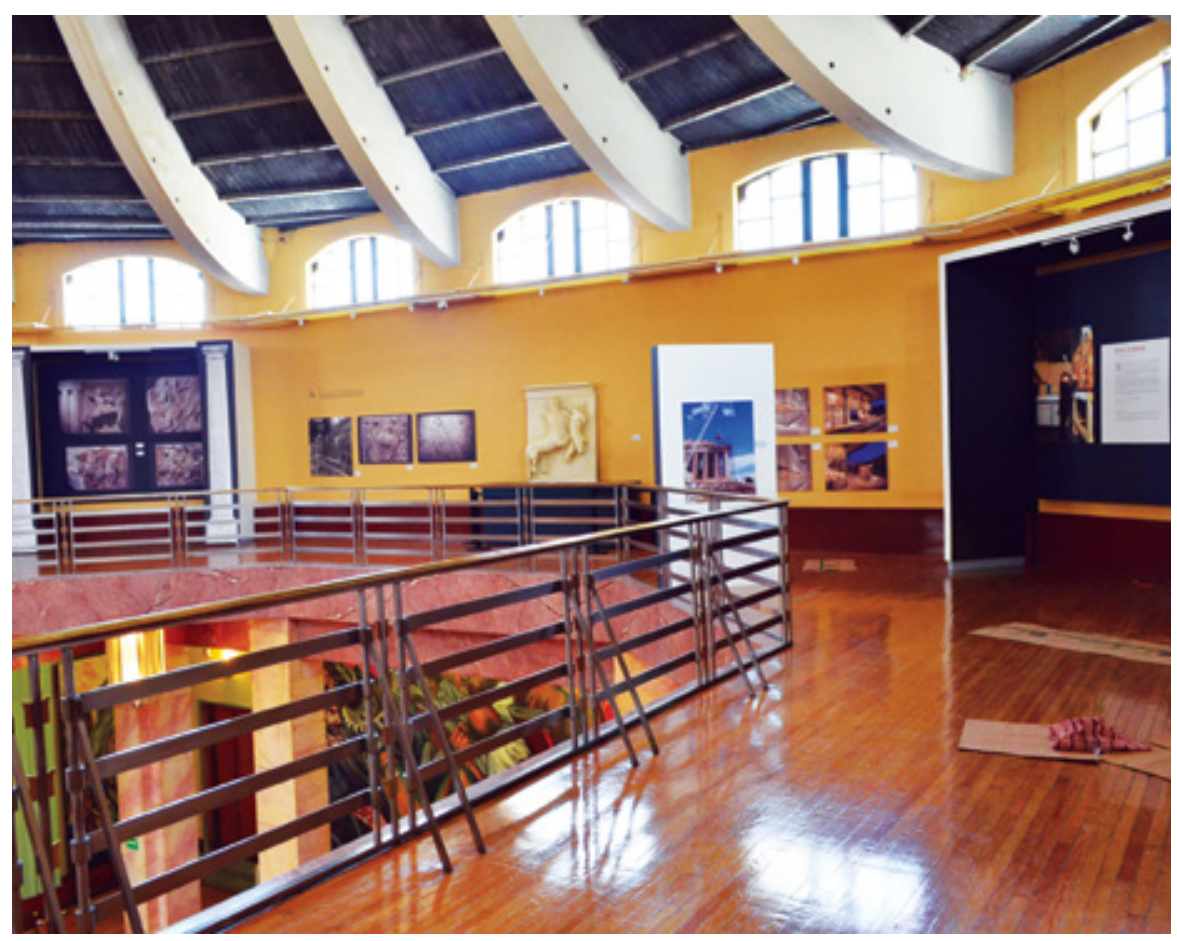

FIGURA 5. Exposición Partenón: arquitectura y arte, muro este; al centro, reproducción del dintel que representa la guerra de los centauros, MNA-INBA, México (Fotografía: Josué Flores, 2013; cortesía: fototeca MNA-INBA, DACPAI-INBA).

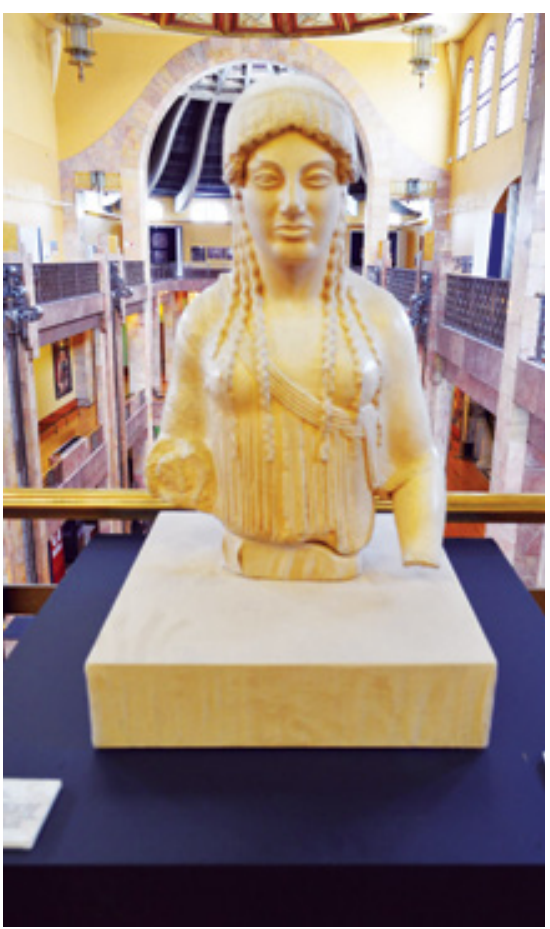

FIGURA 6. Exposición Partenón: arquitectura y arte, reproducción de una koré usada como ofrenda a la diosa Atenea, MNA-INBA, México (Fotografía: Josué Flores, 2013; cortesía: fototeca MNA-INBA, DACPAI-INBA).

la arquitectura. De acuerdo con las directrices tecnológicas actuales, el museo también dispone de un recorrido virtual por las instalaciones y se mantiene en comunicación constante con el público por medio de la red social Facebook.

El equipo de investigación del MNA-INBA, entre el que me cuento, conformó asimismo una exposición conmemorativa por el 80 aniversario de la construcción del PBA-INBA, donde se presentó tanto una selección de planos originales de los arquitectos Adamo Boari, Federico Mariscal $y$ otros que intervinieron en el proyecto, como bocetos, dibujos, perspectivas y maquetas de elementos estéticos del edificio, incluidos bienes culturales que ya son célebres por propio derecho, como el telón de cristal del teatro (Figura 7) y el domo del artista húngaro Géza Maróti que representa a Apolo y las musas (Figura 8).

Concluyo esta breve semblanza del MNA-INBA con varias reflexio- 


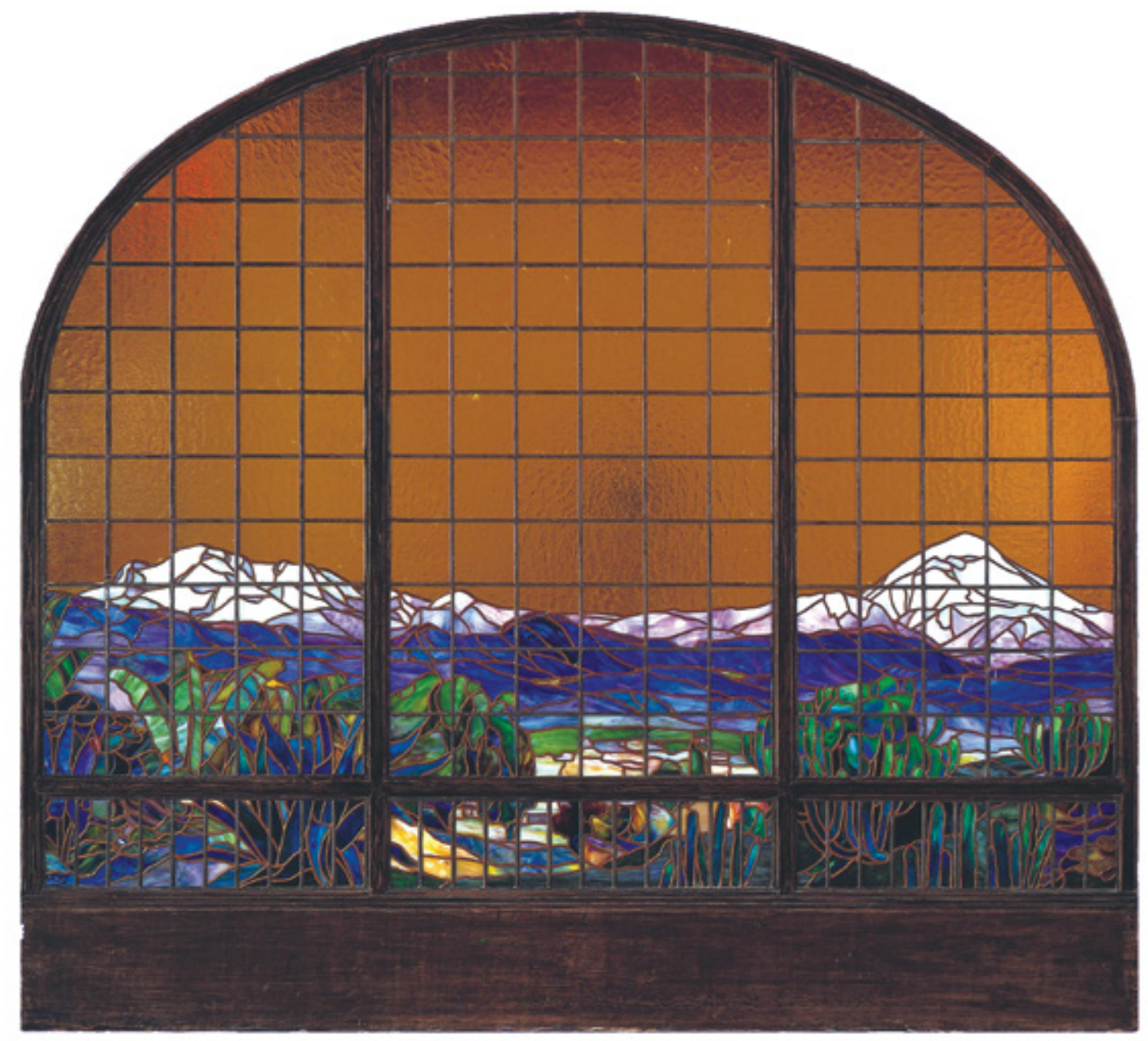

FIGURA 7. Diseño del telón de cristal de la sala principal del Palacio de Bellas Artes, INBA (Maqueta: Geza Maróti ca.1908; cortesía: fototeca DACPAI-INBA).

nes: hoy en día tanto el Departamento de Investigación como el equipo de museografía de este reciento afronta varios retos, entre los que está el establecer más vínculos con universidades, centros de investigación e institutos culturales con el objeto de divulgar las muestras de arquitectura que se han presentado en el museo. Por otra parte, es evidente que tiene la necesidad de lograr una mayor difusión hacia la sociedad en general, para lo que será fundamental, además de aumentar la visibilidad del MNA-INBA, cuya vocación y oferta, por encontrarse en el tercer nivel del PBA — un edificio con considerable visita tanto nacional como internacional-, suelen pasar inadvertidas, solventar las medidas precautorias de acceso (si bien necesarias para el cuidado de un inmueble declarado monumento artístico) que llegan a desalentar a sus visitantes. Asimismo, parece fundamental cambiar la idea de que, por tratarse de un museo especializado, sus contenidos están acotados a los profesionales de la arquitectura. En esta tarea resulta esencial configurar un paquete museográfico que efectivamente acerque la cultura arquitectónica a estudiantes de diferentes grados, y despierte en ellos el interés por una disciplina cuyas obras

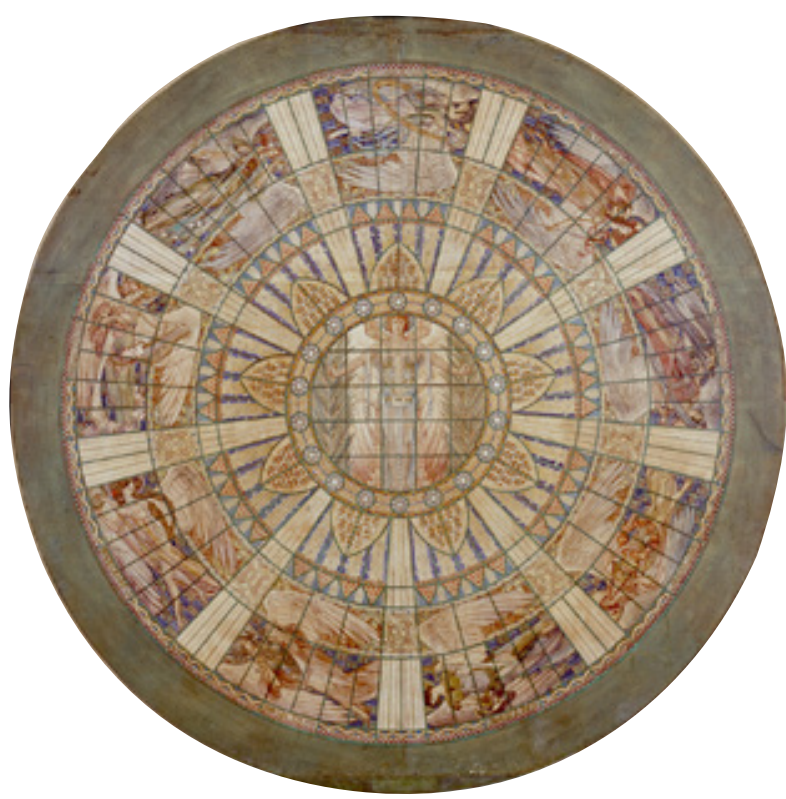

FIGURA 8. Acuarela original del plafón luminoso de cristal de la sala principal del Palacio de Bellas Artes, INBA (Dibujo: Geza Maróti, ca. 1910; cortesía: fototeca). 
están indisolublemente presentes en nuestra cotidianidad. Es mi convicción que será a través del arduo trabajo de investigación y producción museográfica del MNA-INBA como éste mantendrá vigente el objetivo propuesto desde hace 30 años: rescatar, documentar y divulgar la arquitectura nacional e internacional para instrucción y deleite de presentes y futuras generaciones.

\section{Referencias}

INBA

1990 Documentos para la historia de la arquitectura en México 3: El Museo Nacional de Arquitectura, México, INBA/ Conaculta.

Leal, Juan Felipe

2010 Anales del cine en México, 1895-1911. 1901: primera parte. Los teatros-salones, México, Casa Juan Pablos.

Martínez Orralde, Dolores

2014 Comunicación personal, 29 de julio.

MNA-INBA

2014 Compendio de exposiciones del Museo Nacional de Arquitectura, México, MNA-INBA.

Ortiz Híjar, Juan Manuel

2014 Comunicación personal, 4 de agosto.

UNESCO

2015 Lista del Patrimonio Mundial, documento electrónico disponible en [http://portal.unesco.org/es/ev.php-URL_

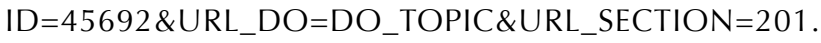
html], consultado en enero de 2015.

\section{Síntesis curricular del/os autor/es}

\section{Cecilia Sánchez Zárate}

Museo Nacional de Arquitectura (MNA),

Instituto Nacional de Bellas Artes (INBA), México

arq_c_sanchez@prodigy.net.mx

Licenciada en arquitectura (Escuela Superior de Ingeniería y Arquitectura [ESIA], Instituto Politécnico Nacional [IPN], México) y maestra en conservación y restauración de bienes culturales inmuebles (Escuela Nacional de Conservación, Restauración y Museografía [eNCRyM], Instituto Nacional de Antropología e Historia [INAH], México). Cuenta con cursos de especialización en museografía y comisariado de obra de arte. Se desempeña como asesora especializada en proyectos de intervención en diferentes despachos y ha impartido ponencias sobre temas relacionados a la valoración y rescate de la arquitectura de siglo XX. Actualmente colabora en la conformación, acondicionamiento y montaje de las exposiciones realizadas en el Museo Nacional de Arquitectura (MNA), Instituto Nacional de Bellas Artes (INBA), México. 